\title{
Study of User Reuse Intention for Gamified Interactive Movies upon Flow Experience
}

\author{
Han Zhe ${ }^{1}$, Lee Hyun-Seok ${ }^{1 *}$
}

\begin{abstract}
As Christine Daley suggested, "interaction-image" is considered to be typical in the age of "Cinema 3.0", which integrates the interactivity of game art and obscures the boundary between producers and customers. In this case, users are allowed to involve actively in the scene as "players" to manage the tempo of the story to some extent, it, thus, makes users pleased to watch interactive movies repeatedly for trying a diverse option to unlock more branch lines. Accordingly, this paper aims to analyze the contributory factors and effect mechanism of users' reuse intention for gamified interactive movies and offer specific concepts to improve the reuse intention from the interactive film production and operation perspectives. Upon integrating the Flow theory and Technology Acceptance Model (TAM) and separating the intrinsic and extrinsic motivations of key factors based on Stimulus-Organism-Response (S-O-R), the research builds an empirical analysis model for users' reuse intention with cognition, design, attitude emotional experience and conducts an empirical analysis on 425 pieces of valid sample data applying SPSS22 and Amos23. The results show that user satisfaction and flow experience impact users' reuse intention highly and perceived usefulness, perceived ease of use, perceived enjoyment, remote perception, interactivity, and flow experience have significant positive influence on user satisfaction experience.
\end{abstract}

Key Words: Gamified Interactive Movies, User Reuse Intention, TAM, Flow Theory.

\section{INTRODUCTION}

Image art itself is on a radical change with the development of technology. The "traditional movie" narrates the stories mainly relying on "the logic of the movement-image". Since 1990, it started to transform to the "modern movie" for "the logic of the time-image [1]", which indicates that "the relationship between images has been replaced by visual and aural performance in body movements and the references with specific meanings have been replaced by pure behaviour description [2]". In this case, Christine Daley, an American scholar for new media imaging, declared that "variability, hypertextualization, and interactivity [3]" are the new characteristics of the "modern movie" and the movie is a cohesive immutable artwork no longer but being involved in a cross-media interactive world. [4]" "Interaction-image" differs from the general linear narrative and the visual fixation mechanism of

passive exposure in film making, it absorbs the interactivity characteristic of game art to redefine the nature of movies, the narrative, the watching experience, and the relationship between audiences and silver screen to a great extent, achieving new visual and aural aesthetic feelings for audiences [5]. In this context, interactive movies are typical for being film art of the age of "Cinema 3.0".

Glorianna Davenport, a scholar, suggested that the interactive movie integrates film language and aesthetics with a delivery system that is capable of realizing audience feedback and control to encourage users to engage in the establishment, personalization, consumption, and sharing activities of film experience [6]. It focuses on the creation of image experience and immersion, and more emphasizes how to trigger users' affect and sensorium via images to draw users in the narration substantially, such a high connection between users and images allows the former to experience whatever the role sees, touches, hears, and feels close, even directly [7].

\footnotetext{
Manuscript received September 30, 2020; Revised November 16, 2020; Accepted November 22, 2020. (ID No. JMIS-20M-10-026) Corresponding Author (*): Hyunseok Lee, (47011) Jurye-ro 47, Sasang-gu, Dongseo University Global Village 205V, Busan, South Korea, +82 10-2423-7239, maegok@ hotmail.com.

${ }^{1}$ Dept. of Visual Contents, Dongseo University, Busan, South Korea, hanzhe0419@gmail.com.
} 
Thus, the interactive movie is capable of creating a strong "sense of being on-site" based on the coordination between digital technique and video and audio language to fade the boundary between virtuality and reality to provide users with the right to choose freely; in turn, users receive immersive watching experience via a string of interaction moves.

Kinoautomat (1967), the world's first interactive film set up both a green button and a red button at every seat in a customized cinema, it required the users to select between two scenes and played the scene chosen by the majority. The emergence of interactive films would be more of providing audiences with the right to choose narrations than integrating technology and film to form a new type of film, satirizing the political reality that resisted free vote in Czechoslovakia [8]. As the developing digital and mobile technologies, achieving the interaction between users via a medium has become the most significant problem. In this case, stream media platforms are considered the hotbeds for current interactive movies for their special "ATAWAD" consumption pattern (i.e., the convenience logic of anytime, anywhere, and any device). Netflix, one of the stream media platform tycoons, has successfully released many children's interactive programs, including Cat in Boots: A Storybook Adventure (2017), Buddy Thunderstruck: Maybe An Envelope (2017), Stretch Armstrong: The Breakout (2017), and Minecraft: Story Mode (2018), thereafter Black Mirror: Bandersnatch, an interactive film, has been discussed intensely in December 2018; in this movie, users are allowed to make diverse options freely on behalf of the role to explore different storylines. Besides, HBO has launched Mosaic (2018), an experimental interactive program, which can only be watched in a specific smartphone app. Youtube, BBC, and Wal-Mart followed to invest interactive contents. AORB (2019) is the first South Korean interactive movie, jointly-produced by Cass and Youtube, the film will pause at about 1 minute 30 seconds for users to select between two options to enter the next video, the whole program will be finished in five rounds [9]. Of course, various steam media platforms across China have been releasing their interactive products such as Prime Suspect (2019; Mystery Type) by Mango TV, His Smile (2019; Young Love Type) by Aiqiyi, and Miss Truth (2020; Costume Mystery Type) by Youku. In addition, bilibili has offered the access for users to produce and upload their interactive videos, and Tencent Video released Antique Trap: Origin of the Buddha Head (2019); unlike other traditional films, its length is 20 minutes and it is equipped with a gamified operation interface, a classic QTE game design, and an abundant interaction mechanism in stronger film techniques. Accordingly, this research considers this film as the subject to explore the contributory factors and effect mechanism of gamified interactive movie users' reuse intention and aims to offer specific concepts to improve the reuse intention from the interactive film production and operation perspectives.

Being a new field, gamified interactive movies' prevalence is inadequate. Given this consideration, the study takes Antique Trap: Origin of the Buddha Head (2019) as the experience subject to build a model for influential factors of users' reuse intention upon flow experience and investigate the impact paths of all the factors. In this case, supported by S-O-R, the research integrates TAM (perceived enjoyment included) and the Flow theory, thereby determining cognition factors (perceived usefulness, perceived ease of use, and perceived enjoyment) and design factors (remote perception and interactivity) are prior variables at the stimulating layer, attitude factor (user satisfaction experience) and emotional experience factors are the intermediary variables at the organism layer, and the reuse intention is at the reaction layer. In light of the existing research references, the study establishes an empirical analysis model for the influential factors of users' reuse intention and suggests hypotheses over the relationships between variables. Further, based on the sample data collected by the questionnaire survey, the study applies SPSS22 and Amos23 to analyze the data and verifies the hypotheses suggested.

\section{THEORETICAL INVESTIGATION}

\subsection{UE-Centered Interactive Movie}

The stitching mechanism of traditional films between cameras and film editing significantly demonstrates the passiveness of audiences. Creators' volitional, conceptual manipulations are behind the mechanism. Users generate a sense of identity because of such stitching, thus losing the initiative to think independently and being introduced into the settled scenarios. In the 1990s, the experimental film was at the initial position of the exploration of interactivity between images and users, people attempted to integrate the contemporary media elements from the image production, watching experience, and other perspectives to provide audiences with more subjectivity. As Peter Lunenfeld, an American scholar, mentioned in an article -- The myth of Interactive Movies, the interactive film can be classified as three forms: (1) the products by Glorianna Davenport director, which trigger the interaction between works and users via an internet demonstration system to generate textual meaning and are closer to documentary-like storytelling; (2) The Erl King (1986) and Sonam (1990) by

Grahame Weinbren, a new media artist, which allow users to manage the transition from one scenario to another in the invisible intercutting: and (3) I am Your Man by Bob Bejan in 1992. The creation allows audiences to control the 
buttons in the seats at special narrative notes to choose the specific roles, following their movement paths. According to the audiences' choices, the roles with various contexts, thus, tell the story from different perspectives and dimensions. Partly, it offers higher discourse power to audiences in the film work, and users can participate in the scenario as players instead of accepting it passively and being managed by the director and screenwriter.

\subsection{Impact of Gamified Interactive Movies on Users' Flow Experience}

\subsubsection{User Experience}

User experience (UE) is a common concept in the fields of human-computer interaction (HCI) and intera ction design [10], which indicates a subjective psycho logical feeling built during users are using the specifi c products or services, covering users' cognition, senti ment, preference, consciousness, physiology and psych ology, behaviour, etc. through the early, middle, and 1 ater stages of the product or service application [11] [12]. According to the experience depth, it divides U $\mathrm{E}$ into three levels. The first level regards the initial UE stage as a subconscious experience, which derives from users' perception of the persistent information $i$ nto brains, thus the experience emerges. The second 1 evel is the accomplishment of the experience process, users feel uniqueness and satisfaction. And the third 1 evel considers a particular application environment, vi ewing UE as a realistic experience and users explore things from the experience [13], [14].

\subsubsection{Gamification}

Richard Bartle suggested the concept of "gamification" in the 1980s; briefly, it means turning none-game subjects (or jobs) into games [15]. This concept has been widely applied since the 21 st century. In the second half of 2010 , it was included by Google Trends. In 2011, the term was selected as one of the annual candidate hot words by Oxford Dictionary, its definition is "adopting gamification mechanism and gamification experience design to inspire and encourage people to achieve the objectives digitally [16]". Therefore, in combinations of different game mechanisms, "gamification" enables none-game contents to generate playful interactivity [17], thereby motivating users' engagement, involvement, and mental loyalty. Gamified interactive movies differ from games for applying gamification elements to realize a general game-like experience taking a game as the agency other than emphasizing rule mechanism.
According to Jane McGonigal, the characteristics of gamification can be summarized as: (1) objective, which attracts audiences' attention and sets directions for them to adjust the engagement constantly; (2) rule, which sets restrictions for players on how to realize the objective. These constraints and barriers make the game highly challenging to motivate players' desire to explore and conquer, in turn, players gain enjoyable emotional experience by conquering the barriers; (3) feedback system, which is based on score, level, progress bar, etc. and promises players that the objective in the game is absolutely achievable to motivate players to continue the game activity; and (4) voluntary participation, which ensures that players can be in and out freely, guaranteeing the game process is voluntary [18].

Moon and Kim (2000) discovered that stronger humancomputer interactivity on the webpage indicates stronger perceived enjoyment of users on the webpage [19]. Specifically, perceived enjoyment is considered as a subjective sense of pleasure of individuals formed in a specific environment. For the design elements in gamified interactive movies, it extracts "remote perception" to measure the general effect of the interaction design and abstracts interactivity as the tendency factor of gamification development for interactive films. The concept, remote perception, was first suggested by D. L. Hoffman et al.'s study on flow experience and denotes users' remote experience and feeling upon a specific environment [20]. In gamified interactive movies, remote perception means that allowing users to have immersive experience during the process by computer, smartphone, or other mobile terminals.

\subsubsection{Flow Experience}

In 1996, Csikszentmihalyi proposed nine constructive dimensions of flow experience: articulate goals, immediate feedback, matched challenges and skills, convergence of behavior and consciousness, strong concentration, potential sense of control, self-consciousness fading, ignorance of time, and purposive experience [21]. Trevino and Webster also raised a descriptive definition for flow state: perceived control of users during the interaction with computers, users think they are focusing on the interaction process, users are curious during the interaction process, and users consider the interaction process enjoyable [22]. Further, Ghani assumed two dimensions to evaluate flow experience: total immersion and enjoyment receiving [23]. Thus, flow experience can be regarded as "a balance between individuals' skills and the task challenges [24]" or "the best experience people can receive from the challenges and skills perceived in a specific environment [25]". Novak and Thomas generalized the nine features of flow experience as 
three conditions, flow can only be formed once the three conditions are satisfied simultaneously [26], see Table 1. A program that can make an individual forget the time is highly entertaining. In this case, HCI has been proven to be crucial to perceived enjoyment upon gamified interactive movies. Users allow then to form flow experience more easily.

Table 1. Three conditions of flow.

\begin{tabular}{|c|c|c|}
\hline Conditional Factor & Experience Factor & Result Factor \\
\hline Articulate Goal & Behavior- & Self- \\
Consciousness & Consciousness \\
Immediate & Convergence & Fading \\
Interaction feedback & Strong & Time Distortion \\
Proper Skills for & Concentration & Self-Purpose \\
Challenges & Sense of Control & Feedback \\
\hline
\end{tabular}

\subsubsection{Reuse Intention}

The reuse intention the paper emphasizes can be interpreted as continuance intention. Currently, flow theory has been extensively applied in usage intention-related research. Hoffma et al. (1996) have demonstrated flow (immersive) experience impacts online buyers' shopping experience significantly and suggested that relevant enterprises shall reform and adapt the flow experience for customers by means of effective marketing management and advertising, thereby enhancing the intention and behaviour of online shopping [27]. Cong Fang conducted empirical research and proved that the customers' flow experience formed during online shopping impacts the intention of online shopping [28]. Wang Na demonstrated, the triggering, concentrating, and total engagement stages of flow experience all impact the usage intention of online users [29].

\subsection{Technology Acceptance Model}

Technology acceptance model was suggested based on the theory of reasoned action (TRA) and apply in investigating individual subjects' acceptance to a new information service system and the influential factors during the application. In 1989, Davis declared the initial theoretical model, which was improved and developed by many subsequent scholars [30]. As for TAM, perceived usefulness and perceived ease of use are stimulated by external factors to impact users' usage attitude, and the utilizing attitude impact users' final usage behavior via the mediator effect of their usage intention. In general, in light of an empirical analysis over users' acceptance behavior for various information service systems in different conditions, it has found that the two prior variables (i.e., perceived usefulness and perceived ease of use) impact significantly the technology acceptance behavior (see Figure 1 for TAM).
In TAM, perceived usefulness is defined as the improvement of an individual's job performance and overall performance the individual perceived after applying a certain information system, and perceived ease of use is considered as the difficulty to apply the system the users perceived.

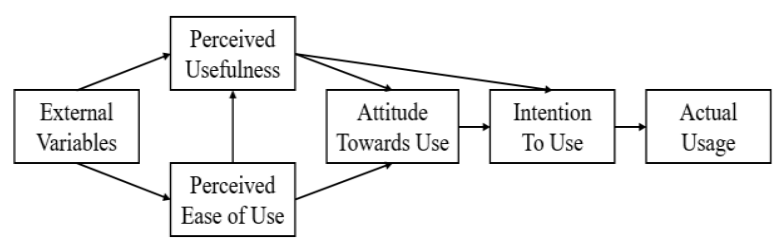

Fig. 1. Technology acceptance model.

\subsection{Stimulus-Organism-Response Model}

Mehrabian and Russel (1974) suggested the stimulusorganism-response model (S-O-R) in process of analyzing the relationship between the external environment and individual behaviors [31]. S-O-R involves stimulating factors, subjects' internal emotions, and behavior outcomes. In this model, external stimulating factors change subjects' internal emotion recognition, and the emotion further impacts the subjects' behavior outcomes as a mediator, eventually inducing the individuals to decide a behavior solution to accept or refuse, as below:

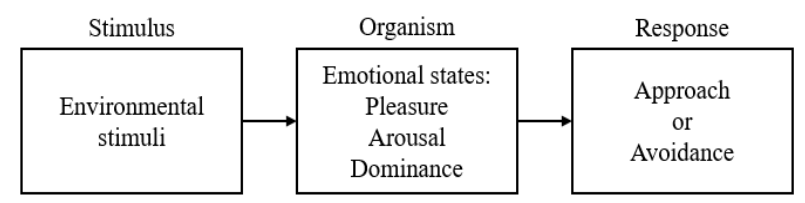

Fig. 2. Stimulus-Organism-Response.

Innovatively, Erpglu applied S-O-R model in network environment amid a study of the impact path of a website's atmosphere on its users' sentiments and behaviors [32]. So far, massive empirical research has been conducted over the application of S-O-R model. Specifically, S-O-R model is capable of classifying and arranging the influential factors of user behaviors; the external factors include environmental stimulation, user cognition, and relevant technological factors, and the subjects' internal factors are mainly their emotion change, attitude, and intention. In this paper, the "users' reuse intention" is the users' behavioral response to constantly prefer a given product. In this case, the paper attempts to arrange the internal and external influential factors of users' reuse intention based on S-O-R model's classification on these factors.

\section{RESEARCH MODEL AND HYPOTHESIS PRESETTING}

\subsection{Research Model}


To build a theoretical model for the influential factors of gamified interactive movie users' reuse intention, the research integrates the Flow theory and TAM to have the factors that impact gamified interactive movie users' reuse intention. Further, it offers definitions to explain the relevant variables concerning the model and suggest hypotheses based on the previous findings; that is conducting a logical derivation over the relationship between five prior variables (cognition factors: perceived usefulness, perceived ease of use, and perceived enjoyment; design factor: remote perception and interactivity), flow experience, users' reuse intention to finally determine the study's empirical analysis model.

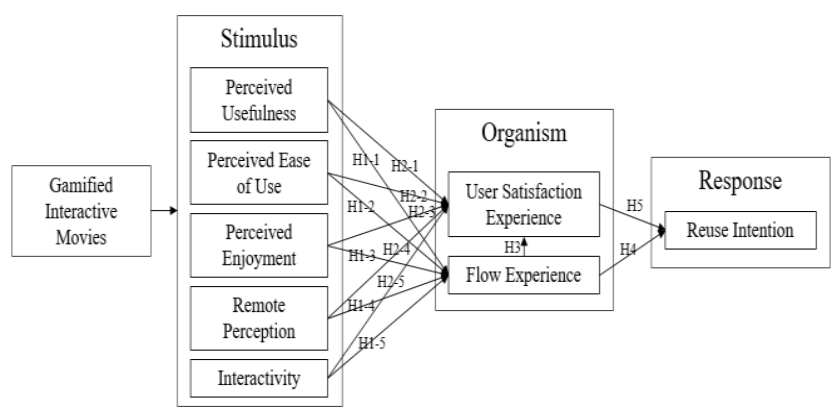

Fig.3. Research model

\subsection{Hypothesis Presetting}

Jacob et al. [33] suggested a reality-based on interaction framework. In this case, an interaction design emphasizes not only how to facilitate users to recognize and operate a given product but also ensuring users to be enjoyable and satisfied emotionally. Such emotional demands are the experience users seek for. According to the research achievements of Chen Jie et al. [34], perceived ease of use contributes to the generation of flow experience. Moreover, Ou Xifan and Tan Hao [35] suggest an interaction design in the premise of being useful, easy to use, and willing to use to promote users to gain better emotional experience. Wang Jun et al. [36] demonstrated perceived usefulness, perceived ease of use, and perceived enjoyment improve users' concentration greatly in the case of applying interactive animation in an App design practice.

According to the findings of Zhou Junjie [37], user interaction is highly capable of reinforcing the stickiness to virtual communities and improving users' accesses; interactive games between users allow then to form flow experience more easily. D. L. Hoffman et al. first suggested the remote perception concept in a conceptual flow experience model to indicate users' remote feeling and experience in each environment [38]. Further, J. Steuer defined remote perception as individuals' perception in a specific environment via a subsidiary media [39]. In smartphone games, remote perception's media is the smartphone, which provides users with immersive experience during the game. G. L. Polites et al. realized that favorable user experience contributes importantly to forming user stickiness [40]. D. Li believed flow experience facilitates users' sustainable usage behavior [41]. Zhao Qing et al. verified flow experience can improve user satisfaction to increase users' stickiness behavior in their study concerning the formation mechanism of internet users' stickiness behavior [42]. Based on the statements above, this paper considers the gamification design for interactive films provides users with entertainment value and allow users to achieve an immersive state to be satisfied psychologically for the positive influential factors concerning access and operation, including convenience, usefulness, etc. Thus, the paper suggests the following hypotheses:

H1: User experience impacts flow experience.

H1-1: Perceived usefulness positively impacts flow experience.

H1-2: Perceived ease of use positively impacts flow experience.

H1-3: Perceived enjoyment positively impacts flow experience.

H1-4: Remote perception positively impacts flow experience.

H1-5: Interactivity positively impacts flow experience.

$\mathrm{H} 2$ : User experience impacts user satisfaction experience.

H2-1: Perceived usefulness positively impacts user satisfaction experience.

H2-2: Perceived ease of use positively impacts user satisfaction experience.

H2-3: Perceived enjoyment positively impacts user satisfaction experience.

H2-4: Remote perception positively impacts user satisfaction experience.

H2-5: Interactivity positively impacts user satisfaction experience.

H3: Flow experience positively impacts user satisfaction experience.

H4: Flow experience positively impacts user reuse intention. H5: Usage intention positively impacts user reuse intention.

\subsection{Operational Definitions of Research Variables}

The research variables that the research model and hypotheses involve include perceived usefulness, perceived ease of use, perceived enjoyment, remote perception, interactivity, user satisfaction experience, flow experience, reuse intention, they shall be specified in operational definitions. 
Table2. Research variables.

\begin{tabular}{|c|c|c|c|c|}
\hline $\begin{array}{l}\text { Latent } \\
\text { Variable }\end{array}$ & Operational Definition & Questionnaire Item & No. & Source \\
\hline \multirow{3}{*}{$\begin{array}{l}\text { Perceived } \\
\text { Usefulness } \\
\text { (PU) }\end{array}$} & \multirow{3}{*}{$\begin{array}{l}\text { The usefulness that users } \\
\text { perceived in the gamified } \\
\text { interactive movie }\end{array}$} & The gamified operation interface is convenient. & PU1 & \multirow{3}{*}{$\begin{array}{l}\text { D. F. Davis [30] } \\
\text { DavisVenkatesh [43] } \\
\text { Hyunsik Choi [44] }\end{array}$} \\
\hline & & $\begin{array}{l}\text { Watching the interactive movie allows me to pass time or } \\
\text { relieve stress. }\end{array}$ & PU2 & \\
\hline & & $\begin{array}{l}\text { The gamified interaction brings me into the story quickly } \\
\text { and allows me to concentrate. }\end{array}$ & PU3 & \\
\hline \multirow{3}{*}{$\begin{array}{l}\text { Perceived } \\
\text { Ease of Use } \\
\text { (PEOU) }\end{array}$} & \multirow{3}{*}{$\begin{array}{l}\text { The simplicity and clarity } \\
\text { of method of application }\end{array}$} & $\begin{array}{l}\text { The changes in the progress bar and favorability in the } \\
\text { interactive movie allow me to know the game process } \\
\text { clearly. }\end{array}$ & $\begin{array}{c}\text { PEOU } \\
1\end{array}$ & \multirow{3}{*}{$\begin{array}{l}\text { D. F. Davis [30] } \\
\text { DavisVenkatesh [43] } \\
\text { Hyunsik Choi [44] }\end{array}$} \\
\hline & & I can watch the video anytime and anywhere. & $\begin{array}{c}\text { PEOU } \\
2 \\
\end{array}$ & \\
\hline & & $\begin{array}{l}\text { The gamified operation procedure is greatly simple and } \\
\text { clear. }\end{array}$ & $\begin{array}{c}\text { PEOU } \\
3 \\
\end{array}$ & \\
\hline \multirow{4}{*}{$\begin{array}{l}\text { Perceived } \\
\text { Enjoyment } \\
\quad(\mathrm{PE})\end{array}$} & \multirow{4}{*}{$\begin{array}{l}\text { Users feel joyful or } \\
\text { interesting using a specific } \\
\text { system }\end{array}$} & $\begin{array}{l}\text { The rich interactive rules entrust the story with unknown } \\
\text { newness. }\end{array}$ & PE1 & \multirow{4}{*}{$\begin{array}{l}\text { Hamari JJ, Sarsa } \\
\text { HKoivisto [45] } \\
\text { FInocencio [46] }\end{array}$} \\
\hline & & $\begin{array}{l}\text { The interactive forms become richer as the unfolding story; } \\
\text { different rules make me enjoyable. }\end{array}$ & PE2 & \\
\hline & & $\begin{array}{l}\text { To achieve the objective of protecting the Buddha head, I } \\
\text { want to conquer the constraints barriers during the process. }\end{array}$ & PE3 & \\
\hline & & I feel bored during the process. & PE4 & \\
\hline \multirow{4}{*}{$\begin{array}{l}\text { Remote } \\
\text { Perception } \\
\quad(\mathrm{RP})\end{array}$} & \multirow{4}{*}{$\begin{array}{l}\text { The realistic experience } \\
\text { users feel via design } \\
\text { factors like image and } \\
\text { sound using a specific } \\
\text { system }\end{array}$} & $\begin{array}{l}\text { In the story, the master is fighting with the Japanese } \\
\text { invaders deadly, I seem to experience the intense scene } \\
\text { personally and feel an extraordinarily strong sense of } \\
\text { reality. }\end{array}$ & RP1 & \multirow{4}{*}{$\begin{array}{l}\text { Hoffman D. L.T.PNovak } \\
{[20]}\end{array}$} \\
\hline & & $\begin{array}{l}\text { The interactive movie is nicely produced with a strong } \\
\text { sense of pictures. }\end{array}$ & RP2 & \\
\hline & & $\begin{array}{l}\text { The interactive movie is with good playability and } \\
\text { interactive design. }\end{array}$ & RP3 & \\
\hline & & $\begin{array}{l}\text { The interactive movie allows me to feel emotion changes } \\
\text { (happy, nervous, angry, etc.). }\end{array}$ & RP4 & \\
\hline \multirow{3}{*}{$\begin{array}{l}\text { Interactivity } \\
\text { (I) }\end{array}$} & \multirow{3}{*}{$\begin{array}{l}\text { Users produce interactive } \\
\text { behaviours during the } \\
\text { experience }\end{array}$} & $\begin{array}{l}\text { The interactive movie is provided with convenient social } \\
\text { sharing channels. }\end{array}$ & I1 & \multirow{3}{*}{$\begin{array}{l}\text { Ou CXPA, Davison R } \\
\text { MPavlou [47] } \\
\text { Duan Feifei, Zhai } \\
\text { Shanshan [48] }\end{array}$} \\
\hline & & $\begin{array}{l}\text { The interactive movie is provided with abundant social } \\
\text { modules between users (online interaction, unlocked story } \\
\text { display, favorability display, etc.). }\end{array}$ & $\mathrm{I} 2$ & \\
\hline & & $\begin{array}{l}\text { I can choose my preset conception and modify the } \\
\text { following plot according to the clues. }\end{array}$ & $\mathrm{I} 3$ & \\
\hline \multirow{3}{*}{$\begin{array}{l}\text { User } \\
\text { Satisfaction } \\
\text { Experience } \\
\text { (US) }\end{array}$} & \multirow{3}{*}{$\begin{array}{l}\text { Users have positive or } \\
\text { negative subjective } \\
\text { judgments or behaviour } \\
\text { trends for the gamified } \\
\text { interactive movie }\end{array}$} & The time-limited operating mode makes me feel contented. & US1 & \multirow{3}{*}{$\begin{array}{l}\text { Seongho Lee [49] } \\
\text { Da-Wn Jung [50] } \\
\text { D. F. Davis [30] } \\
\text { DavisVenkatesh[43] }\end{array}$} \\
\hline & & $\begin{array}{l}\text { I can trigger different subsequent clues with different } \\
\text { operations, the unknown is interesting. }\end{array}$ & US2 & \\
\hline & & I feel enjoyable after the application. & US3 & \\
\hline \multirow{3}{*}{$\begin{array}{l}\text { Flow } \\
\text { Experience } \\
(\mathrm{FE})\end{array}$} & \multirow{3}{*}{$\begin{array}{l}\text { Users produce } \\
\text { concentrated, enjoyable } \\
\text { mental states watching the } \\
\text { gamified interactive movie }\end{array}$} & $\begin{array}{l}\text { I need to give order immediately for dramatic twists and } \\
\text { intense situations, I am so concentrated that lost self- } \\
\text { consciousness. }\end{array}$ & FE1 & \multirow{3}{*}{$\begin{array}{l}\text { D.L. NovakHoffman [51] } \\
\text { ChengYung-Ming [52] }\end{array}$} \\
\hline & & $\begin{array}{l}\text { I am curious about the unlocked plots and want to unlock } \\
\text { other storylines. }\end{array}$ & FE2 & \\
\hline & & $\begin{array}{l}\text { The rich interaction mechanism entrusts the plot with } \\
\text { massive unknown newness, I am immersive and feel time } \\
\text { flies. }\end{array}$ & FE3 & \\
\hline \multirow{3}{*}{$\begin{array}{l}\text { Reuse } \\
\text { Intention } \\
(\mathrm{RU})\end{array}$} & \multirow{3}{*}{$\begin{array}{l}\text { Users produce frequent } \\
\text { watching behaviour for the } \\
\text { gamified interactive movie } \\
\text { and the usage intention will } \\
\text { last to the future }\end{array}$} & I want to recommend to my friends this interactive movie. & RU1 & \multirow{3}{*}{$\begin{array}{l}\text { BhattacherjeeA [53] } \\
\text { D. F. Davis [30] } \\
\text { Da-Wn Jung [50] }\end{array}$} \\
\hline & & $\begin{array}{l}\text { I want to try different options to unlock more subline } \\
\text { stories. }\end{array}$ & RU2 & \\
\hline & & The gamified operation interface is convenient. & RU3 & \\
\hline
\end{tabular}




\section{EMPIRICAL ANALYSIS}

\subsection{Questionnaire and Information Collection}

The study adopts the questionnaire method at the verification stage. According to the research model and a table concerning the quality of relevant studies in China and abroad, the paper preliminarily designs a questionnaire for the influential factors of gamified interactive movie users' reuse intention based on TAM and the Flow theory. The questionnaires are released via wjx.cn, with 30 questions in total; Question 1-5 aim to investigate the subjects' basic information, the others are presented by Likert scale (1 indicates completely disagree, 5 indicates completely agree). The subjects who do not have experience of watching interactive films are required to watch the interactive movie--Antique Trap: Origin of the Buddha Head (2019) and answer the questions according to their individual experience. The research invited 40 users to conduct a pilot study to analyze the overall reliability and validity of the questionnaires, the questionnaires will be distributed more widely after modifying some linguistic expression according to the preliminary results. The official questionnaire survey started from August 15, 2020 to September 7, 2020. Altogether, 450 questionnaires have been received, in which 425 were available eliminating invalid samples, the sample rate was $94.4 \%$.

\subsection{Descriptive Statistic Analysis of Sampling Distribution}

In general, the samples' demographic variables involve sex, age, education level, etc. Besides, the research includes subjects' watching experience for interactive films in the demographic variable investigation considering it may be an influential factor on users' reuse intention, see Table 3. Specifically, the ratio of male and female is 53.2:46.8, being balanced relatively; for the age distribution, 18-35 audiences are the majority for $74.8 \%$; for education distribution, high school and technical secondary school samples occupy $92.2 \%$; the occupation distributions of student, company employee, public institution, and freelancer are relatively average for $28.2 \%, 19.8 \%, 27.8 \%$, and $19.3 \%$ respectively. In addition, from the watching experience perspective, "never" and " $3-5$ " items occupy $93.6 \%$, which indicates interactive films rarely have extensive audiences as an emerging film subject.

\subsection{Reliability and Validity Analysis}

Reliability test mainly involves global consistency checking of the scale and internal consistency checking of various observation indexes upon the constructs. The formal research scale's global consistency considers
Cronbach's $\alpha$ as the judging criteria, and the internal consistency of the constructs takes composite reliability as the judging criteria.

The Cronbach's $\alpha$ of various constructs refer to Table 4, the results show that the values of Cronbach's $\alpha$ are between 0.771 and 0.863 , exceeding 0.7 (threshold), indicating the measurement indexes upon the constructs are highly related to each other and a favorable global internal consistency of the scale.

Table 3. Descriptive statistic analysis of samples.

\begin{tabular}{|c|c|c|c|}
\hline \multicolumn{2}{|r|}{ Category } & Number & Ratio \\
\hline \multirow{2}{*}{ Sex } & Male & 226 & $53.2 \%$ \\
\hline & Female & 199 & $46.8 \%$ \\
\hline \multirow{5}{*}{ Age } & Under 18 & 99 & $23.3 \%$ \\
\hline & $18-25$ & 144 & $33.9 \%$ \\
\hline & $26-35$ & 174 & $40.9 \%$ \\
\hline & $36-45$ & 6 & 1. $4 \%$ \\
\hline & 45 and Above & 2 & $0.5 \%$ \\
\hline \multirow{3}{*}{ Education } & $\begin{array}{c}\text { High School/ } \\
\text { Technical Secondary } \\
\text { School }\end{array}$ & 194 & $45.6 \%$ \\
\hline & $\begin{array}{c}\text { College/ } \\
\text { Undergraduate }\end{array}$ & 198 & $46.6 \%$ \\
\hline & Master and Above & 33 & $7.8 \%$ \\
\hline \multirow{5}{*}{ Occupation } & Student & 120 & $28.2 \%$ \\
\hline & Company Employee & 84 & $19.8 \%$ \\
\hline & Public Institution & 118 & $27.8 \%$ \\
\hline & Freelancer & 82 & $19.3 \%$ \\
\hline & Others & 21 & $4.9 \%$ \\
\hline \multirow{4}{*}{$\begin{array}{l}\text { Watching } \\
\text { Experience }\end{array}$} & Never & 107 & $25.2 \%$ \\
\hline & $1-2$ & 130 & $30.6 \%$ \\
\hline & $3-5$ & 161 & $37.9 \%$ \\
\hline & 5 and Above & 27 & $6.4 \%$ \\
\hline
\end{tabular}

Table 4. Checking table for construct reliability.

\begin{tabular}{|c|c|c|}
\hline Factor & Cronbach's a & Number of Terms \\
\hline PU & 0.801 & 3 \\
\hline PEOU & 0.771 & 3 \\
\hline PE & 0.863 & 4 \\
\hline RP & 0.810 & 4 \\
\hline I & 0.816 & 3 \\
\hline US & 0.814 & 3 \\
\hline FE & 0.832 & 3 \\
\hline RU & 0.804 & 3 \\
\hline Global Scale & 0.909 & 26 \\
\hline
\end{tabular}


Composite reliability is an index to evaluate the internal consistency of latent constructs, the higher value of composite reliability indicates a higher correlation between various measurement indexes upon the constructs, in other words, the better consistency of the measurement indexes. The calculation formula of composite reliability is:

$$
\rho_{c}=\frac{\left(\sum \lambda\right)^{2}}{\left[\left(\sum \lambda\right)^{2}+\sum \theta\right]}
$$

Tabachinca and Fidell (2007) noted, "ideally, the factor loading would be larger than 0.71 ; in an excellent condition, the loading would exceed 0.63 ; in a favorable condition, the loading would exceed 0.55 , at this point the factor can explain $30 \%$ of the variations of the observation variables.

This paper conducts confirmatory factor analysis applying AMOS23 to obtain the factor loadings, construct composite reliability values, and model fitting indexes of various observation items as shown in Table 5. The factor loadings measured in this research all exceed 0.55 , the minimum construct composite reliability is 0.775 , exceeding 0.6(threshold), GFI(Goodness of Fit Index) $>0.90$, RMSEA(Root Mean Square Error of Approximation) <0.05, CFI(Comparative Fit Index $)>0.90$. verifying there is a robust correlation between the measurement indexes upon various constructs and a favourable internal consistency of the constructs.

Validity impacts the study's reliability or the results' accuracy. In this case, researchers tend to adopt validity as the assessment criteria of the quality of a given study. In this paper, it applies confirmatory factor analysis (CFA); in other words, it measures convergent validity and discriminant validity. The former indicates the measurement of the correlation between a single construct's indexes, the higher correlation, the better convergent validity; and the latter takes effect by mainly exploring the standardized loading coefficients and AVE [54]. The calculation formula of AVE is:

$$
\rho_{v}=\frac{\left(\sum \lambda^{2}\right)}{\left[\left(\sum \lambda^{2}\right)+\sum \theta\right]}
$$

The results are shown in Table 5, the average variances extracted (AVE) of the constructs is between 0.524 and 0.628 , exceeding 0.5 , indicating a stronger correlation between the measurement indexes upon various constructs; it reflects the meaning of the constructs efficiently to certify the scale is with a favorable convergent validity.

\begin{tabular}{|c|c|c|c|c|c|}
\hline \multicolumn{3}{|c|}{ Path } & $\begin{array}{c}\text { Factor } \\
\text { loadings }\end{array}$ & $\mathrm{CR}$ & AVE \\
\hline PU1 & $\rightarrow$ & \multirow{3}{*}{$\mathrm{PU}$} & 0.721 & \multirow{3}{*}{0.804} & \multirow{3}{*}{0.578} \\
\hline PU2 & $\rightarrow$ & & 0.740 & & \\
\hline PU3 & $\rightarrow$ & & 0.817 & & \\
\hline PE0U1 & $\rightarrow$ & \multirow{3}{*}{ PEOU } & 0.714 & \multirow{3}{*}{0.775} & \multirow{3}{*}{0.536} \\
\hline PEOU2 & $\rightarrow$ & & 0.681 & & \\
\hline PEOU3 & $\rightarrow$ & & 0.796 & & \\
\hline PE1 & $\rightarrow$ & \multirow{4}{*}{$\mathrm{PE}$} & 0.859 & \multirow{4}{*}{0.869} & \multirow{4}{*}{0.628} \\
\hline PE2 & $\rightarrow$ & & 0.683 & & \\
\hline PE3 & $\rightarrow$ & & 0.666 & & \\
\hline PE4 & $\rightarrow$ & & 0.930 & & \\
\hline RP1 & $\rightarrow$ & \multirow{4}{*}{$\mathrm{RP}$} & 0.740 & \multirow{4}{*}{0.815} & \multirow{4}{*}{0.524} \\
\hline RP2 & $\rightarrow$ & & 0.762 & & \\
\hline RP3 & $\rightarrow$ & & 0.699 & & \\
\hline RP4 & $\rightarrow$ & & 0.693 & & \\
\hline I1 & $\rightarrow$ & \multirow{3}{*}{ I } & 0.749 & \multirow{3}{*}{0.821} & \multirow{3}{*}{0.605} \\
\hline I2 & $\rightarrow$ & & 0.761 & & \\
\hline I3 & $\rightarrow$ & & 0.821 & & \\
\hline US1 & $\rightarrow$ & \multirow{3}{*}{ US } & 0.799 & \multirow{3}{*}{0.832} & \multirow{3}{*}{0.622} \\
\hline US2 & $\rightarrow$ & & 0.765 & & \\
\hline US3 & $\rightarrow$ & & 0.802 & & \\
\hline FE1 & $\rightarrow$ & \multirow{3}{*}{$\mathrm{FE}$} & 0.737 & \multirow{3}{*}{0.814} & \multirow{3}{*}{0.59} \\
\hline FE2 & $\rightarrow$ & & 0.781 & & \\
\hline FE3 & $\rightarrow$ & & 0.791 & & \\
\hline RU1 & $\rightarrow$ & \multirow{3}{*}{ RU } & 0.763 & \multirow{3}{*}{0.808} & \multirow{3}{*}{0.585} \\
\hline RU2 & $\rightarrow$ & & 0.720 & & \\
\hline RU3 & $\rightarrow$ & & 0.808 & & \\
\hline $\begin{array}{l}\text { Fit }: \mathrm{X}^{2} / \mathrm{d} \\
\text { CFI }=0.980\end{array}$ & 345 & RMS & $\begin{array}{ll}029, & \mathrm{G} \\
77 & \end{array}$ & $\overline{0.940,}$ & $\mathrm{SFI}=0.92$ \\
\hline
\end{tabular}

Table 5. Confirmatory factor analysis.

Discriminant validity denotes the difference that can be distinguished between the construct indexes; ideally, these indexes shall have a low correlation. In this case, the study suggests a comparative method for the correlation coefficient between constructs and the AVE; in other words, it determines whether the AVE of constructs is higher than the correlation coefficient between the construct and the others. The constructs have a favorable discriminant validity if the square root of the AVE value is greater than the correlation coefficient between the two constructs [55]. The square root values of the AVE of the 8 constructs and the correlation coefficient values between the constructs calculated have been shown in Table 6. The results show that the square root values all exceed the correlation. 
Table 6. Test Results of Discriminant Validity.

\begin{tabular}{|c|c|c|c|c|c|c|c|c|}
\hline & $\mathrm{PU}$ & $\begin{array}{c}\text { PEO } \\
\text { U }\end{array}$ & PE & RS & I & US & $\mathrm{FE}$ & $\mathrm{RU}$ \\
\hline PU & 0.76 & & & & & & & \\
\hline $\begin{array}{c}\mathrm{PE} \\
\mathrm{O} \\
\mathrm{U}\end{array}$ & $\begin{array}{l}0.23 \\
7^{* *}\end{array}$ & $\begin{array}{c}0.73 \\
2\end{array}$ & & & & & & \\
\hline $\mathrm{PE}$ & $\begin{array}{l}0.19 \\
6 * *\end{array}$ & $\begin{array}{l}0.36 \\
2 * *\end{array}$ & $\begin{array}{c}0.79 \\
2\end{array}$ & & & & & \\
\hline $\mathrm{RP}$ & $\begin{array}{l}0.26 \\
4 * *\end{array}$ & $\begin{array}{l}0.26 \\
1^{* *}\end{array}$ & $\begin{array}{c}0.39 \\
4 * *\end{array}$ & $\begin{array}{c}0.72 \\
4\end{array}$ & & & & \\
\hline I & $\begin{array}{l}0.20 \\
7^{* *}\end{array}$ & $\begin{array}{l}0.20 \\
1^{* *}\end{array}$ & $\begin{array}{l}0.20 \\
7^{* *}\end{array}$ & $\begin{array}{l}0.19 \\
2^{* *}\end{array}$ & $\begin{array}{c}0.77 \\
8\end{array}$ & & & \\
\hline US & $\begin{array}{c}0.34 \\
6^{* *}\end{array}$ & $\begin{array}{l}0.38 \\
7 * *\end{array}$ & $\begin{array}{c}0.39 \\
1 * *\end{array}$ & $\begin{array}{c}0.39 \\
5^{* *}\end{array}$ & $\begin{array}{c}0.30 \\
5^{* *}\end{array}$ & $\begin{array}{c}0.78 \\
9\end{array}$ & & \\
\hline $\mathrm{FE}$ & $\begin{array}{l}0.35 \\
7 * *\end{array}$ & $\begin{array}{l}0.42 \\
6^{* *}\end{array}$ & $\begin{array}{l}0.43 \\
6^{* *}\end{array}$ & $\begin{array}{l}0.42 \\
9 * *\end{array}$ & $\begin{array}{l}0.33 \\
4 * *\end{array}$ & $\begin{array}{l}0.51 \\
6 * *\end{array}$ & $\begin{array}{c}0.76 \\
8\end{array}$ & \\
\hline $\begin{array}{l}\mathrm{R} \\
\mathrm{U}\end{array}$ & $\begin{array}{c}0.33 \\
3 * *\end{array}$ & $\begin{array}{l}0.47 \\
2 * *\end{array}$ & $\begin{array}{c}0.50 \\
5^{* *}\end{array}$ & $\begin{array}{c}0.34 \\
9 * *\end{array}$ & $\begin{array}{c}0.23 \\
9 * *\end{array}$ & $\begin{array}{l}0.46 \\
6^{* *}\end{array}$ & $\begin{array}{l}0.49 \\
7 * *\end{array}$ & $\begin{array}{c}0.76 \\
5\end{array}$ \\
\hline
\end{tabular}

coefficient values between the constructs in the row and column, which proves the research's constructs have favourable discriminant validity. The bold value at the diagonals are the square root values of the AVE of the 8 constructs, the others are the correlation coefficient values between the constructs. According to the correlation analysis, the cognition factors and design factors are positively correlated with flow experience and user satisfaction experience greatly, and flow experience and user satisfaction experience are positively correlated with user reuse intention, yet the positive correlation does not mean significant influence. Thus, a linear regression analysis is required.

\subsection{Hypothesis Testing}

In this section, the paper aims to verify the hypothesis analysis result. In light of the model's fit indexes, $\mathrm{X}^{2} / \mathrm{df}=1.345 \quad(<5), \quad \mathrm{GFI}=0.940 \quad(\geq 0.9), \quad \mathrm{RMSEA}=0.029$ $(<0.08), \quad$ AGFI $=0.923 \quad(\geq 0.8), \quad$ CFI $=0.980 \quad(\geq 0.9)$, $\mathrm{RMR}=0.036(<0.05), \mathrm{TLI}=0.977(\geq 0.9)$, all the indexes meet the model's fit requirements, demonstrating a favourable fitting between the model and the data.

Considering the overall sample structure model (Figure 4) and the standardized regression coefficients of the hypothetical path relationships (Table 7), the study has the following conclusions. Perceived usefulness positively impacts flow experience significantly $(\beta=0.20, \mathrm{P}<0.001)$. Perceived ease of use positively impacts flow experience significantly $(\beta=0.25, \quad \mathrm{P}<0.001)$. Perceived enjoyment positively impacts flow experience significantly $(\beta=0.18$, $\mathrm{P}<0.001)$. Remote perception positively impacts flow experience significantly $(\beta=0.24, \mathrm{P}<0.001)$. Interactivity positively impacts flow experience significantly $(\beta=0.17$, $\mathrm{P}<0.001)$. Perceived usefulness positively impacts user satisfaction experience $(\beta=0.15, P<0.01)$. Perceived ease of use positively impacts user satisfaction experience $(\beta=0.23$, $\mathrm{P}<0.01)$. Perceived enjoyment positively impacts user satisfaction experience $(\beta=0.17, \quad \mathrm{P}<0.01)$. Remote perception positively impacts user satisfaction experience $(\beta=0.20, P<0.01)$. Interactivity positively impacts user satisfaction experience $(\beta=0.14, \mathrm{P}<0.01)$. Assuming $\mathrm{H} 1$ and $\mathrm{H} 2$ are supported and the impact of user experience on flow experience is more significant than on user satisfaction experience.

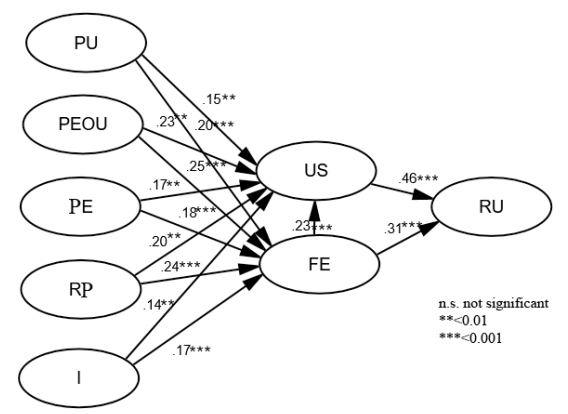

Fig. 4. Verification figures according to the analysis results.

Table 7. Testing results of the model's hypothesis.

\begin{tabular}{|c|c|c|c|c|c|c|c|}
\hline \multicolumn{2}{|c|}{$\begin{array}{l}\text { Hypothe } \\
\text { sis }\end{array}$} & \multicolumn{3}{|c|}{ Path } & $\begin{array}{l}\text { Factor } \\
\text { loadings }\end{array}$ & $\mathrm{P}$ & $\begin{array}{c}\text { Resu } \\
\text { lt }\end{array}$ \\
\hline \multirow{5}{*}{$\begin{array}{l}\mathrm{H} \\
1\end{array}$} & H1-1 & $\begin{array}{l}\text { Perceived } \\
\text { Usefulness }\end{array}$ & $\rightarrow$ & \multirow{5}{*}{$\begin{array}{l}\text { Flow } \\
\text { Experie } \\
\text { nce }\end{array}$} & 0.20 & 0.000 & $\begin{array}{c}\text { supp } \\
\text { ort }\end{array}$ \\
\hline & H1-2 & $\begin{array}{l}\text { Perceived } \\
\text { Ease of Use }\end{array}$ & $\rightarrow$ & & 0.25 & 0.000 & $\begin{array}{c}\text { supp } \\
\text { ort }\end{array}$ \\
\hline & H1-3 & $\begin{array}{l}\text { Perceived } \\
\text { Enjoyment }\end{array}$ & $\rightarrow$ & & 0.18 & 0.000 & $\begin{array}{c}\text { supp } \\
\text { ort }\end{array}$ \\
\hline & H1-4 & $\begin{array}{l}\text { Remote } \\
\text { Perception }\end{array}$ & $\rightarrow$ & & 0.24 & 0.000 & $\begin{array}{c}\text { supp } \\
\text { ort }\end{array}$ \\
\hline & H1-5 & Interactivity & $\rightarrow$ & & 0.17 & 0.000 & $\begin{array}{c}\text { supp } \\
\text { ort }\end{array}$ \\
\hline \multirow{5}{*}{$\begin{array}{l}\mathrm{H} \\
2\end{array}$} & $\mathrm{H} 2-1$ & $\begin{array}{l}\text { Perceived } \\
\text { Usefulness }\end{array}$ & $\rightarrow$ & \multirow{5}{*}{$\begin{array}{c}\text { User } \\
\text { Satisfa } \\
\text { ction } \\
\text { Experie } \\
\text { nce }\end{array}$} & 0.15 & 0.001 & $\begin{array}{c}\text { supp } \\
\text { ort }\end{array}$ \\
\hline & $\mathrm{H} 2-2$ & $\begin{array}{l}\text { Perceived } \\
\text { Ease of Use }\end{array}$ & $\rightarrow$ & & 0.23 & 0.002 & $\begin{array}{c}\text { supp } \\
\text { ort }\end{array}$ \\
\hline & $\mathrm{H} 2-3$ & $\begin{array}{l}\text { Perceived } \\
\text { Enjoyment }\end{array}$ & $\rightarrow$ & & 0.17 & 0.007 & $\begin{array}{c}\text { supp } \\
\text { ort }\end{array}$ \\
\hline & $\mathrm{H} 2-4$ & $\begin{array}{l}\text { Remote } \\
\text { Perception }\end{array}$ & $\rightarrow$ & & 0.20 & 0.002 & $\begin{array}{c}\text { supp } \\
\text { ort }\end{array}$ \\
\hline & $\mathrm{H} 2-5$ & Interactivity & $\rightarrow$ & & 0.14 & 0.009 & $\begin{array}{c}\text { supp } \\
\text { ort }\end{array}$ \\
\hline & $\mathrm{H} 3$ & $\begin{array}{c}\text { Flow } \\
\text { Experience }\end{array}$ & $\rightarrow$ & $\begin{array}{c}\text { User } \\
\text { Satisfa } \\
\text { ction } \\
\text { Experie } \\
\text { nce }\end{array}$ & 0.23 & 0.000 & $\begin{array}{c}\text { supp } \\
\text { ort }\end{array}$ \\
\hline & $\mathrm{H} 4$ & $\begin{array}{c}\text { Flow } \\
\text { Experience }\end{array}$ & $\rightarrow$ & Reuse & 0.31 & 0.000 & $\begin{array}{c}\text { supp } \\
\text { ort }\end{array}$ \\
\hline & H5 & $\begin{array}{c}\text { User } \\
\text { SatisfactionE } \\
\text { xperience }\end{array}$ & $\rightarrow$ & $\underset{n}{\text { Intentio }}$ & 0.46 & 0.000 & $\begin{array}{c}\text { supp } \\
\text { ort }\end{array}$ \\
\hline
\end{tabular}

Fit: $\mathrm{X}^{2} / \mathrm{df}=1.345, \mathrm{RMSEA}=0.029, \mathrm{GFI}=0.940, \mathrm{AGFI}=0.923$ $\mathrm{CFI}=0.980, \mathrm{RMR}=0.036, \mathrm{TLI}=0.977$ 
Then, flow experience positively impacts user satisfaction experience significantly $(\beta=0.23, \mathrm{P}<0.001)$, flow experience positively impacts reuse intention significantly $(\beta=0.31, \quad \mathrm{P}<0.001)$, and user satisfaction experience impacts reuse intention significantly $(\beta=0.46$, $\mathrm{P}<0.001)$. Assuming $\mathrm{H} 3, \mathrm{H} 4$, and $\mathrm{H} 5$ are supported. It can be found that the impact of user satisfaction experience on reuse intention is more significant by comparison over the standardized influence coefficients of user satisfaction experience and flow experience on user reuse intention.

\section{CONCLUSION}

Based on S-O-R model, this paper integrates the Flow theory and TAM to confirm cognition factors (perceived usefulness, perceived ease of use, and perceived enjoyment) and design factors (remote perception and interactivity) are prior variables at the stimulating layer, attitude factor (user satisfaction experience) and emotional experience factors are the intermediary variables, and reuse intention is the dependent variable, thereby establishing an empirical model. In this case, the research explores the intrinsic mechanisms of perceived usefulness, perceived ease of use, perceived enjoyment, remote perception, and interactivity to impact interactive movie users' reuse intention from the gamification design and users themselves dimensions. The findings show that perceived usefulness, perceived ease of use, perceived enjoyment, remote perception, and interactivity positively impact user flow experience significantly, perceived usefulness, perceived ease of use, perceived enjoyment, remote perception, and interactivity positively impact user satisfaction experience, flow experience positively impacts user satisfaction experience significantly, and flow experience and user satisfaction experience positively impact user reuse intention significantly.

In this case, users' perceived usefulness, perceived ease of use, perceived enjoyment, remote perception, and interactivity have been proven to be the dominant contributory factors of user flow experience and satisfaction experience. Previous scholars' studies mostly focused on the development of interactive film and other theoretical perspectives. However, in the case of the rapid development of mobile internet, the market share of mobile terminals cannot be underestimated, and theoretical research can hardly verify the real feelings that interactive movie users experience. Based on the S-O-R model, this paper combines TAM and Flow models to have an empirical analysis to expound the contributory factors of user reuse intention more distinctly. Also, user flow experience and satisfaction experience are playing an agent for these relevant factors to impact user reuse intention. In this research, the model involves flow experience and user satisfaction experience, they are the medium, explanatory variables shall embody their effects on user reuse intention via these two intermediate variables, and flow experience impacts user satisfaction experience positively. The result offers a clear idea for the enterprises concerning interactive movies to reserve users; in other words, it improves users' reuse intention by optimizing user flow experience and satisfaction.

The findings also provide some practical inspiration for the development and preservation of gamified interactive movies. Firstly, for the design of interactive films, it may introduce social systems in interactive movies to improve the movies' interactivity and enhance the communication between users other than emphasizing gamification operation and film techniques, thereby improving users' reuse intention. From the marketing perspective, it may simplify the access channels for interactive movies. The unique characteristics of mobile terminals can also contribute to users' reuse intention for interactive movies. Secondly, from the content dimension, the fineness of interactive movie design and the playability of gamification are playing an important role for an interactive movie's production and generalization; a high-quality interactive movie shall be capable of creating users high fidelity virtual environment experience to improve users' flow experience. Based on this conclusion, the related enterprises shall exploit the rapidly developing cinematic and gaming technologies to produce finer interactive movies. At the same time, it is crucial to understand the properties of the user group of interactive movies; for instance, it may expend efforts on the social systems and picture production according to the different themes and styles of the interactive movies. Besides, the production of interactive films may involve the detection of users' flow experience by market research, embedded questionnaire for user experience in the games, etc.

Likely, the paper has some limitations. On the one hand, interactive movies can be considered innovative. Given most users have never been exposed to it, this research is considerably restricted for it requires those who have no experience of watching an interactive film to finish the questionnaire based on merely Antique Trap: Origin of the Buddha Head (2019); in this case, the theme and related elements are limited. On the other hand, for the study contents, this paper considers the gamification design and users themselves due to the limitation of study conditions, which inevitably results in the neglect of other research focuses and factors. Overall, the study perspectives are inadequate.

\section{REFERENCES}

[1] DeleuzeLouis ReneGilles, Cinema 2: The Time-Image. 
Changsha: Hunan Fine Arts Press, 2004.

[2] David Rodowick, Gilles Deleuze's Time Machine. Durham. NC: Duke University Press, 1997.

[3] DalyKristen, Cinema 3.0: How digital and computer technologies are changing cinema. New York: Columbia University, 2008.

[4] DalyKristen, "Cinema 3.0: The Interactive-Image," Cinema Journal, p. 33, 2010.

[5] DalyKristen, "Cinema 3.0: The Interactive-Image," Cinema Journal, p. 86, 2010.

[6] Glorianna Davenport, The Johns Hopkins Guide to Digital Media. Baltimore: John Hopkins University Press, 2014.

[7] Kang Wenzhong, Sun Shaoyi, "The perceptual revolution of screen images: from attractive films to experiential films," Journal of Shanghai University (Social Science Edition), p. 37, 2018.

[8] Gyeunkyung, "Space of the Interactive Film-Virtual Space, Cyberspace, Remmediation Space," Contemporary Cinema Research Institute, pp. 10-11, 2019.

[9] KongSoo-Kyung, "The Effect of Color on Narratives in Interactive Video," Journal of Digital Contents Society, pp. 2049-2050, 2019.

[10] KongSoo-Kyung, "The Effect of Color on Narratives in Interactive Video," Journal of Digital Contents Society, pp. 2049-2050, 2019.

[11] Sato Keiichi, " User experience and behavior based on the design information framework," Journal of Northwest University: Natural Science Edition, pp. 389-394, 2012.

[12] Zhao Yuxiang, Zhu Qing, Hua Zhangping, " The Theoretical Perspective of User Experience Design in Social Media: Motivation Support Model and Design Principles," Chinese Library Journal, pp. 36-45, 2011.

[13] Deng Shengli, " Research Progress of Foreign User Experience," Library and Information Work, pp. 43-45, 2008.

[14] J.Dewey, Art as experience. Penguin. JD BROWNE $\mathrm{G}, 2005$.

[15] Kevin Weibach, Gamification thinking: a new force that will change the future of business. Hangzhou: Zhejiang People's Press, 2014.

[16] Brian Bok, Gamification design. Wuhan: Huazhong University of Science and Technology Press, 2017.

[17] J. S. Hwang, LeeMcMillan, "Effects of Structural and Perceptual Factors on Attitudes Toward the Website," Journal of Advertising, 2003.

[18] Jane McGonigal, Games change the world. Hangzhou: Zhejiang People's Press, 2012.

[19] G. J. W., Kim Y. Moon, "Extending the TAM for a
World-Wide-Web Context," Information \& Management, pp. 217-230, 2001.

[20] Hoffman D LT PNovak, "Marketing in hypermeadia computer-mediated environments: conceptual foundations," Journal of marketing, pp. 50-68, 1996.

[21] MCsikszentmihalyi,Creativity: Flow and the Psychology of Discovery and Invention. New York: Harper Collins, 1996.

[22] Trevino L kJWebster, "Flow in computer-mediated communication electronic mail and vice," Communication Rasearch, pp. 539-573, 1992.

[23] Ghani J A, S P.Deshpande, "Task Characteristics and the Experience of Optimal Flow in Human," The Journal of Psychology, pp. 381-391, 1994.

[24] Leone CJBurns, "The Measurement of Locus of Control: Assessing More Than Meets the Eye," The Journal of Psychology, pp. 63-76, 2000.

[25] Edwards J RA J, Cooper C LBaglioni, "Examining the relationships among self-report measures," Journal of Applied Psychology, p.440, 1990.

[26] PNovak \& Thomas, "Internet marketing: influences, themes and directions," University of Southern California, pp. 3-7, 1999.

[27] Huang, "Designing website attributes to induce experiential encounters," Computers in Human Behavior, pp. 425-442, 2003.

[28] LiBrowne, "Towards an understanding of the behavioral intention to use a web site," International Journal of Information Management, pp. 197-208, 2006.

[29] CairnsBrown and PaulEmily, "A grounded investigation of game immersion," Human Factors in Computing Systems, pp. 1297-1300, 2004.

[30] D. F. Davis, "Perceived usefulness, perceived ease of use, and user acceptance of information technology," MIS Quarterly, pp. 319-340, 1989.

[31] Mehrabian A, J A.Russell, "An approach to environmental psychology ," MIT, 2017.

[32] Eroglu S A, K.A, Davis L MMachleit, "Atmospheric qualities of online retailing," Journal of Business Research, pp. 177-184, 2001.

[33] Wang Yushan, Li Shiguo, " The value and application of emotional memory in interaction design," Packaging engineering, pp. 56-59, 2011.

[34] Chen Jie, Cong Fang," Research on Influencing Factors of Online Consumers' Buying Behavior Based on the Perspective of Flow Experience," Nankai Management Review, pp. 132-140, 2009.

[35] Ou Xifan, Tan Hao, " Research on Internet Product Design Based on Flow Theory," Packaging engineering, pp. 70-74, 2016.

[36] Wang Jun, Xiao Chang, Yang Yi, " Research on user 
focus and immersion model in APP animation design," Packaging engineering, pp. 114-121, 2020.

[37] Zhou Junjie, " User stickiness in the context of social commerce: the indirect influence of user interaction," Management Review, pp. 127-136, 2015.

[38] PD L, NOVAK THOFFMAN, "Marketing in hypermedia computer mediated environments: conceptual foundations," Journal of marketing, pp. 5068, 1996.

[39] JSTEUER, "Defining virtual reality: dimensions determining telepresence," Journal of communication, pp.73-93, 1992.

[40] Al.L.P, CLAY K.W, ELENA K, etG R ETA, "A theoretical framework for consumer E-Satisfaction and site stickiness: an evaluation in the context of online hotel reservations," Journal of organizationacomputing

\&electronic commerce, pp. 1-37, 2012.

[41] WETHE RBELI, "Why do internet users stick with a specific web site? A relationship perspective," International journal of electronic commerce, pp. 105141, 2006.

[42] Zhao Qing, Zhang Li, Xue Jun, " The Formation Mechanism and Empirical Analysis of the Sticky Behavior of Internet Users," Information Theory and Practice, pp. 25-29, 2012.

[43] DavisVenkatesh and F. D.V, "A theoretical extension of the technology acceptance model: Four longitudinal field studies," Management Science, pp. 186-204, 2000.

[44] Hyunsik Choi, " (A) study on the effects of moblile information services and customers characteristics on tourist satisfaction and reuse intention, " Ph.D. dissertation," Ph.D. dissertation, Korea Aerospace University, 2009.

[45] Hamari JJ, Sarsa HKoivisto, "Does Gamification Work? -A Literature Review of Empirical Studies on Gamification," the 47th Hawaii International Conference on System Sciences, 2014.

[46] FInocencio, "Using Gamification in Education: A Sys tematic," Literature Review, 2018.

[47] Ou CXPA, Davison R MPavlou, "Swifi Guanxi in online marketplaces: the role of computer-mediated communication technologies," Mis Quarterly, pp. 209230, 2014.

[48] Duan Feifei, Zhai Shanshan," Research on the Mechanism of Mobile Game User Stickiness: Integrating Flow Theory and TAM Theory," Library and Information Work, pp. 21-38, 2017.

[49] Seongho Lee, "(The)Effects of ubiquitous attributes of mobile contents on perceived interactivity and behavioral outcome," Ph.D. dissertation, Graduate School of Business Administration, Seoul National

University, 2006.

[50] Da-Wn JungJun AhnHyung, "Impact of the Characteristics of Docent Mobile Apps on User Satisfaction and Intention to Re-use," The Korea Contents Association, pp. 329-341, 2016.

[51] D.L. NovakHoffman, Yung, Y. F.T.P, "Measuring the customer experience in online environments: a structural modeling approach," Marketing Science, pp. 22-42, 2000.

[52] ChengYung-Ming, "Exploring the roles of interaction and flow in explaining nurses," elearning acceptance, p. 33, 2013.

[53] Bhattac herjeeA, "Understanding information systems continuance: an expectation-confirmation model," MIS Quarterly, pp. 351-370, 2001.

[54] R. O. Mueller, Basic principles of structural equation modeling: Anintroduction to Lisrel and Eqs, Springer Verlag, 1996.

[55] C. Fornell, and D. F. Larcker, "Evaluating structural equation models with unobservable variables and measurement error," Journal of Marketing Research, pp. 39-50, 1981.

\section{Acknowledgement}

This work was supported by Dongseo University, "Dongseo Cluster Project" Research Fund of 2020 (DSU20200010).

Authors

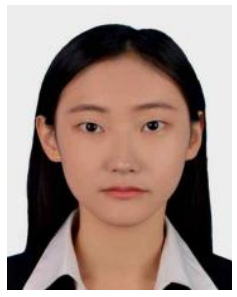

Han Zhe received her bachelor's deg ree in visual communication design fr om Zhongnan University of Economic $s$ and Law in China in 2016. Obtain ed a master's degree from the Depart ment of Visual Contents of Dongseo University in 2019. Currently, her joi ned the Department of Visual Conten ts for pursuing her $\mathrm{PhD}$ degree at $\mathrm{D}$

ongseo University.

Her research interests include Animation, visual culture, semiotics, representation theory, User experience, animation film industry development, interactive design.

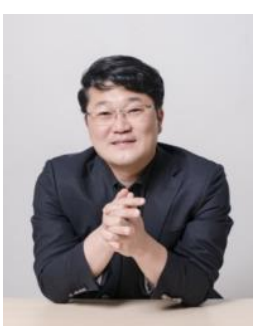

writing

In 2017, through project-based self-study to produce VFX creative content of VFX, 2015 Smart Learning Space, an educational method that supports creativity and talent Invention
Hyunseok Lee received his $\mathrm{PhD}$ in animation from Loughborough Univ ersity, UK in 2012. He is the head of the Graduate School of Visual Content at Dongseo University, wh ere he runs a research laboratory $r$ elated to digital content. He also ha $\mathrm{s}$ his own Korean-style online publ ic lectures (K-MOOC) related to a nimation. His latest works include: 
Journal of Multimedia Information System VOL. 7, NO. 1, March 2020 (pp. 221-228): ISSN 2383-7632 (Online) http://doi.org/10.33851/JMIS.2020.7.1.000

project, 2018 Korean-style online public lecture [K-MOOC], 2018 National Research Foundation of Korea: The Function of Illustrated Images in Candlelight Assembly to Express Political Will, 2016 National Research Foundation of Korea: Proposal of Solution for Realistic Bombing and Liquid Effects in Visual Effects, 2016 National Research Foundation of Korea: A Practical Proposal on the use of Educational Animation to Prevent Accidents, 2014 National Research Foundation of Korea: A Study on the Educational Method of Brigham Young University and the Ethical Function of Animation.

He is currently in Zhongnan University of Economics \& Law, in China, as a visiting professor. 